\title{
Model job description for consultant child and adolescent psychiatrists
}

\author{
Stephen Littlewood and Kedar N. Dwivedi
}

In June 1997, the Royal College of Psychiatrists published an occasional paper entitled Model Consultant Job Descriptions. The Faculty of Child and Adolescent Psychiatry Regional Representatives considered that further guidance was required to assist those writing job descriptions and for Regional Representatives assessing the job descriptions in consultation with Regional Advisors, on behalf of the Royal College. Hence, this Faculty document, which may additionally be helpful for those contemplating applying for consultant posts.

Adherence to the format laid out in this paper will produce a more consistent quality of job descriptions in child and adolescent psychiatry. It is more likely that the new posts will emerge as attractive, safe and professionally fulfilling. Regional representatives in their role as speciality advisors in child and adolescent psychiatry will be encouraged to recommend the approval of child and adolescent psychiatry posts which follow this guidance.

Comments in square brackets represent information, which should be supplied under each heading. Italicised questions are to be asked by the assessor, as he or she reads the job description.

\section{Section 1: job description}

The post

1. Job title.

2. Type of post. [Indicate if 'joint', 'special responsibility' or 'special interest' post.]

3. Is the job full- or part-time? [It should be explicit that consideration will be given to part-time applicants for full-time posts.]

4. Number of sessions allocated. [There should be no more than six fixed sessions for a full-time post, or three for a part-time post. Changes will occur only as mutually agreed.]

5. Based at a hospital or clinic. [Quality of accommodation should be judged against recommendations by Kurtz (1992).]
Does it include a day unit and in-patient unit?

Is there sufficient accommodation for permanent professional and secretarial staff and trainees?

Is the ownership of accommodation by health, local authority or otherwise?

6. Principal duties

(a) Clinical.

(b) Liaison (with other agencies).

(c) Management.

(d) Teaching and training.

(e) Research and audit.

IIn whichever order is appropriate to the post.]

Are there any expectations regarding subspeciality work or any contractual obligations to produce expert reports: for example, in relation to child protection?

Are these realistic?

7. On-call responsibilities (including emergency on-call).

Is there responsibility for medical (paediatric) liaison or a para-suicide service? Is there middle grade cover for in-patient units? Is there an out of hours on-call requirement? What is the rota? Is this first or second on? If first on, who could call? (hospital consultants, general practitioners, social workers, police . . .?). If second on, who is first on? (child psychiatrists, specialist registrars, paediatricians, adult psychiatrists . . .?). What is the age cut off? (16 or 18 or school-leaving age?). Does this on-call include an out of hours overdose assessment function? Is there pay or time off in lieu for this on call?

[Define clinical, legal and employment responsibilities when covering out of hours and the geographical area covered.]

Where are beds to admit psychiatric emergencies to? Is there an agreement to admit 16-18-year-olds in adult psychiatric units? [If no out of hours responsibility, the job description should define responsibilities for overdose assessments, emergency 
psychiatric assessments and urgent requests for diagnosis (see also Job plan section).]

\section{Population and services}

1. Catchment area of the post, including the local population served per consultant. ICompare with recommended College 'norm' and include multiplier of 1.6 for teaching districts (Royal College of Psychiatrists, 1983).]

2. Details of age range of patients for whom this post-holder will be responsible.

Are children of the whole range of intelligence seen?

If not, what are the arrangements for children with learning disabilities?

What are the facilities for young people who misuse substances?

3. Nature and extent of local private and voluntary sector residential, nursing home and other facilities (if appropriate).

4. Purchasers and contracts. [Provide an outline of the main requirements relating to the post and the service for the principal purchasers.]

Clinical prioritisation

What is the process for negotiation of priorities between the trust and the purchaser? [The consultant should be directly involved in this process.] Is there a mechanism for review?

How is the waiting list organised?

Do the purchasers specify priorities, for example, diagnosis and treatment of major psychiatric disorder $v$. sexual abuse work $v$. preventative work in the community?

Is the job realistic or is it asking the impossible?

\section{Responsibilities}

[There needs to be clarity about the consultant's personal responsibilities, given the resources available, for example, what spectrum of cases he or she will be responsible for assessing and treating and for what will he or she not be responsible.

The trust needs to contract appropriately with the purchaser to protect consultant's interests especially for the most seriously ill patients whose safe care may be beyond the resources of a small district service.

Contracts and service level agreements

[Ideally job descriptions should include a copy of the current service level agreement which for the consultant is likely to be in the range of 1-3 new cases per week, depending on the service (see Job plan section of this document).] Is the case mix specified?
Is there a development and investment plan for the service?

Has there been a recent needs assessment project?

5. The trust

IA good description would include a brief history, the component parts, the essentials of the management and decision making structure and arrangements for medical representation.]

What is the position of the child and adolescent mental health service in the management structure of the trust, (e.g. clinical directorate or sub-directorate)?

What is the professional background of the service managers?

What is the coherence of the service provision?

Who is accountable for contract performance?

6. Details of local characteristics that may be experienced, such as, inner city problems. and any geographical difficulties in providing the service.

7. Details of development plans for local psychiatric services with a time-scale for these developments.

8. Number of consultants in the trust and in the speciality (with names). Relevant details of neighbouring trusts providing psychiatric services if relevant.

9. Number of special responsibility posts in the trust.

10. Details of district community paediatrics and hospital paediatrics.

Is there an integrated model of child health services?

11. Details of local statutory services, for example, in-patient and day-patient facilities, including number of beds and day places.

12. Details of links with local agencies, for example, social services, education. Are boundaries coterminous?

13. Details of regional and supra-regional services in the speciality (that is, arrangements for psychiatric beds/admissions).

\section{Research, audit and teaching}

1. Number of trainees to be supervised for one hour per week each.

2. An indication of approximate balance between service provision and teaching commitments.

3. Teaching expected on MRCPsych course and higher training seminars.

4. Research time available.

5. Audit time available and expected. 
6. Teaching of medical students and other links expected with local university.

7. Training of non-medical staff.

\section{The team (medical and non-medical)}

1. List of staff by discipline, grade and source of funding, for example social services, education.

2. Likely extent of support/assistance from staff grade psychiatrists.

3. Number of other support staff sessions available.

4. Details of community psychiatric nurse support (if appropriate).

5. Administration of any Committee, planning groups etc.

6. Secretarial time available for all aspects of consultant's work (at each site, if the post has more than one base). (They should be dedicated to the child and mental health service and of appropriate seniority and experience to carry out their multiple roles.]

7. Office space/consultation room(s) available at each site.

8. Space for teaching purposes available.

9. Statement of expected management relationships between consultant and other members of the multi-disciplinary team.

\section{Service, clinical and professional structures}

1. Composition of the consultant team. [Consultant teams are multi-disciplinary and can include representatives from nursing. social work, occupational therapy, clinical psychology and others.]

2. Role of consultant in leadership of the service and in supervising other team members. [The consultant is likely to take on the most challenging and complex cases, while mild or moderate disorders should be seen by other team members.]

3. Lines of clinical responsibility.

If others in the service take clinical responsibility, how is this organised?

4. Development and planning of the psychiatric service.

Whose responsibility is this?

5. Details of management structure within the service and to which it relates, and lines of managerial accountability of the child psychiatrist and other team members.

6. Access to Tler 4 services

What is the nature of the contract in relation to the following?

(a) In-patient psychiatric units for children and adolescents. (b) Specialist services, for example, forensic, neuropsychiatry, eating disorders etc.

(c) Arrangements for local use of paediatric and psychiatry beds. [Clarity of responsible medical officer responsibility when this occurs.]

What is the budget for the service and who is the budget holder?

7. List of colleagues, in associated medical specialities. [E.g. in acute and community paediatrics, general psychiatry, learning disabilities, drug and alcohol services.]

\section{Criteria for judging the job description}

The consultant's job description must be realistic and should allow them to participate effectively in:

1. Leadership within the multi-disciplinary team.

2. Developing and planning of the psychiatric service.

3. Offering expert advice on clinical issues.

4. Continuing management responsibilities.

5. The administration of the unit.

6. The maintenance of long-term casework with individual patients.

7. The management of violent incidents.

8. Maintaining up to date continuing professional development.

\section{Miscellaneous}

1. Salary range and terms and conditions (a) Is this a Whitley Council medical and dental terms and conditions or a trust terms and conditions? If so how is it different from The Whitley Councll terms and conditions? How are they negotiated?

(b) [Clarify complaints, grievance and disciplinary procedures.]

(c) Is mental health officer status preserved? [For this, the contract may have to be a minimum of nine clinical sessions.]

(d) What are the arrangements for study leave, continuing professional development and professional leave? What is the budget available for these? How is cover organised for study leave, continuing professional development and annual leave?

What are the arrangements for travelling expenses and removal expenses?

(a) Is a staff crèche avallable?

2. Personal specification from the trust or other employer should outline the required 
and desirable qualities they wish to see in the successful candidate.

3. Application details should include a point of contact for further information, clear instructions on applying for the post and a brief outline of the sort of enquiries it would be reasonable for a possible applicant and a short-listed applicant to make.

4. A contact name of an individual familiar with the post should be provided, so that the candidate can discuss the job description with them.

\section{Section 2: the job plan}

Since 1979 a whole time consultant contract in the National Health Service does not specify hours to be worked but is a 'professional' contract. The only difference in a 10 notional half-days (NHDs) maximum part-time contract is that one can exceed the $10 \%$ limit on private practice earnings. (There is no implication that a whole time contract is therefore 11 NHDs.)

A part-time contract is 10 NHDs or less and represents a fixed commitment of time. For more detail about consultant contracts it is useful to consult the British Medical Association Consultant Handbook.

\section{The Rule of Thirds}

Many consultant contracts for child psychiatrists look more like contracts for senior house officers. They demand huge volumes of clinical casework and wide ranging responsibilities for acute assessments, as well as demanding all the other functions of a consultant.

The Rule of Thirds suggest that a third of the time should be devoted to direct clinical work, a third to indirect clinical work and a third to other consultant duties.

For example, for a standard whole time job plan:

Direct clinical (four direct sessions)

One new case session

Two follow-up/treatment sessions

One session for emergency/unplanned assessments

Indirect clinical sessions (3-4 indirect sessions) One session for supervision of others' clinical work Two sessions for administration correspondence/case conferences information gathering/ team meetings

One paediatric or other liaison session

Other consultant duties (3-5 sessions depending on job plan balance)

One session for continuing professional development
One session for audit

One session for management dutles/service development

(One session for teaching and training)

(one session for advisory duties including College duties)

(Sessions of academic work or research including any honorary senior lecturer sessions)

Official travel (if working on a number of sites)

Please note that on-call duties are direct clinical work: for example, a one in two first consultant on-call to the district would take perhaps two sessions of a job plan, a one in five with junior doctor cover might be one session of a job plan.

Depending on the nature of the work liaison work may be either direct clinical or indirect clinical. It is probably acceptable for audit to be either indirect clinical or part of 'other consultant duties'.

The Rule of Thirds should not be confused with British Medical Association advice that consultants should only enter between five and seven fixed sessions into their personal job plans.

In order that a consultant can function at a consultant level and take on broader supervisory, managerial and advisory roles in a service it is necessary to limit their direct clinical work load to reasonable levels. In general, the consultant would expect to be taking on the most challenging cases in the service, which need the highest levels of skills. Mild to moderate disorders should be seen by other members of the team or in Tler 1 services.

Jobs, which are fragmented geographically over two or more sites, will need allowance to be made for this, as it will impinge on the capacity for direct and other clinical work.

In some parts of the country there has been a history of very rapid turnover of child and adolescent psychiatry consultants as a result of the posts being unfulfiling, clinically exhausting and undervaluing the expertise of the consultant. The aim of setting down criteria for the job plan is to enable the consultants to take on fulfilling jobs in which they choose to remain, and to enable the building up of good quality services around this consistent medical leadership.

In order for this to happen, a recommendation of a range from 1-3 new cases per week seen by the consultant would seem to be reasonable. This figure will vary according to resources for treatment and style of the service. Time for direct treatment from the consultant would be relatively limited in the two follow-up sessions in the job plan and so the more straightforward treatment work might best be passed on to other team members after the consultant has made an assessment. This would depend on the style of work in the team. 
Children with very severe mental illness

In a typical small, district service of 100000 population, between two and four severely mentally ill children will present in the course of a year. Their management is usually beyond the resources of small, district out-patient services, and it is important that the consultant child and adolescent psychiatrist is not asked to take responsibility for sick patients whom he or she has not the resources to safely manage. There appears to be a national shortage of appropriate, safe adolescent psychiatry facilities for severely ill adolescents under the age of 16 years. If the policy is for such children to be placed on adult psychiatry wards then the contractual arrangements for this should be clearly defined through a separate service level agreement made between the purchasers and the adult psychiatry services. A child mental health service could reasonably expect to be making its specialist opinions available to those services when children with severe mental illness are admitted.

\section{Part-time contracts}

These represent a fixed commitment. Note that these cannot reasonably carry continuing responsibility, and an employer cannot insist on out of hours work, but the part-timer may volunteer this (with appropriate sessional allowance in the job plan). A 'travel' component of $\mathbf{3 0}$ minutes is allowable at the beginning and end of each session of a part-timer's job plan. For an eight-session contract travel, therefore, could theoretically be up to eight hours of working time (which is equivalent to over two NHDs). It should be noted that the continuing professional development responsibilities of part-timers and the College requirements for time spent on continuing professional development are identical for part-timers and full-timers.

\section{Continuing responsibility}

This clause forms part of a standard consultant contract. It has particular relevance where there are in-patients, but for out-patients services the child and adolescent psychiatrist could be said to be offering consultancy to the general practitioner who continues to hold 'continuing responsibility'. If continuing responsibility is required of a child psychiatrist, it should be duly stated how this responsibility should be discharged and what resources are available to do this. (Note the distinction between continuing responsibility for existing patients, and the provision of a 24hour emergency assessment service for new patients.) These are both potentially costly provisions in terms of child psychiatrist's sessional time, given the infrequency of acute presentations of mental illness in those under the age of 16 .

\section{Acknowledgements}

The authors would like to recognise the contribution made by many colleagues in the preparation of this final document, members of the Regional Representatives Group and the Chair and members of the Executtve of the Faculty for Child and Adolescent Psychiatry.

\section{References}

KURTZ, Z. (1992) With Health in Mind: Mental Health Care for Children and Young People. London: Action for Sick Children.

Royal College of Psychiatrusts (1983) Providing a district service for child and adolescent psychiatry: medical manpower priority. Bulletin of the Royal College of Psychiatrists, 7. 94-97.

- (1997) Model Consultant Job Descriptions. Occasional Paper OP39. London: Royal College of Psychiatrists.

*Stephen Littlewood, Consultant Child Psychiatrist for Ellesmere Port and Regional Representative for Mersey: Family \& Child Therapy Service, Clinic Centre, Stanney Lane, Ellesmere Port, Cheshire CH65 9AE and Kedar N. Dwivedi, Chair of Regional Representatives, Faculty of Child and Adolescent Psychiatry. Royal College of Psychiatrists

\section{*Correspondence}

